\title{
Hormone Replacement Therapy (Hrt) for Postmenopausal Periodontitis
}

\author{
Salvatore Privitera* \\ Department of Biomedical and Biotechnological Sciences, University of Catania, Italy \\ *Corresponding author: Salvatore Privitera, Department of Biomedical and Biotechnological Sciences, University of Catania, Italy
}

Submission: 㭗 October 24, 2017; Published: 㭗 December 11, 2017

\section{Opinion}

Current importance about Hormone Replacement Therapy (HRT) issues, due to the high incidence of periodontal diseases, has prompted researchers to investigate the possibilty of associations between periodontitis and specific women's health issues. This increase is due by the increase in life expectancy, the scientific evolution of medical knowledge and the increased educational and cultural levels of society [1].

Women in particular may undergo a decrease in bone mass during menopause, affecting sites such as the alveolar and jaw bones, which secondarily produces periodontal-gingival-tooth disease, bringing us closer to the possibility of being able to avoid and/ or treat the sequelae of this disease. The menopause is a physiological process that takes place in the fourth-fifth decade of a woman's life, when permanent cessation of menstruation occurs, and is based on hormonal changes that will result in a series of general clinical manifestations as an increase in the symptoms of periodontal disease, including the exhibition of more severe attachment loss than premenopausal women, but the possible influence of some secondary effects of the menopause - such as osteoporosis/ osteopenia - as modifying factors in loss of periodontal attachment is still the subject of some debate $[2,3]$.

Increasing numbers of women are using HRT and estrogens for replacement therapy during menopause to relieve climacteric symptoms (hot flashes, sweating, vaginal dryness, oral alterations, etc.) and increase their quality of life. HRT includes oral administration, oestrogen containing dermal patches and tibolone. Natural human estrogens are E2, estrone (E1) and estriol (E3), and their conjugates, i.e. the sulfuric acid esters and glucuronic acid esters [1,4]. In Europe the predominant estrogen for HT has been E2 [5]. whereas in the US conjugated equine estrogen is most commonly used [6]. Progestagens are divided into natural progesterone and synthetic progestagens. The most common progestagen used in US is medroxyprogesterone acetate (MPA), while in Europe MPA is used to a lesser extent $[5,6]$.

Synthetic steroid tibolone, various phytoestrogens, testosterone and selective estrogen-receptor modulators are used under some conditions as alternatives to traditional HRT and, of these, only tibolone is useful in treating vasomotor symptoms [4,7-9]. Until recently, HRT was considered the single most effective treatment of menopausal symptoms and was recommended for the prevention of diseases associated with estrogen deficiency [1,2,7,9-11]. After the publication of the Women's Health Initiative, the use of HRT has been questioned [11].

Recent analyses of the WHI data and other randomized controlled trials, however, have suggested that the potential risks involved in taking HRT (increased risk of breast cancer, cardiovascular outcomes and stroke) may largely depend on the estrogen and progesterone/progestin formulation, dosage, mode of administration, patient's age, associated diseases, and duration of treatment. Therefore, based on the current evidence, the intention, dose and regimen of HRT need to be individualized, based on the principle of choosing the lowest appropriate dose in relation to the severity of symptoms and age at onset of menopause [9-11].

In past years, various studies have been conducted to evaluate the effect of HRT in modifying the periodontal conditions in postmenopausal women due to a possible connection between osteoporosis and periodontitis [12-19].

HRT was associated with a reduction of alveolar bone loss, but a number of studies failed to find an inverse correlation between alveolar bone density and severity of periodontal disease [20-22]. Furthermore, some authors failed to demonstrate any beneficial effect of HRT on alveolar bone density/height [23,24].

HRT has also been associated with decreasedlevels of gingival bleeding. It has been suggested that estrogen may have an inhibitory effect on gingival inflammation by inhibiting mediators (IL-1, TNF-, IL-6, IL-1b, IL-8) and cellular mechanism of inflammation [12,25]. Conflicting results exist on the effects of HRT on probing pocket depth and attachment level [18-20,22,25]. In somestudies the risk of tooth loss was found to be lower in women who used HRT than those who did not [23,26-29].

However, further studies should address the biological mechanisms underlying this effect. 


\section{References}

1. Lobo RA, Pickar JH, Stevenson JC, Mack WJ, Hodis HN (2016) Back to the future: Hormone replacement therapy as part of a prevention strategy for women at the onset of menopause. Atherosclerosis 254: 282-290.

2. Honour JW (2017) Biochemistry of the menopause. Ann Clin Biochem 1: 4563217739930.

3. Bacon JL (2017) The Menopausal Transition. Obstet Gynecol Clin North Am 44(2): 285-296.

4. Botteri E, Støer NC, Sakshaug S, Graff-Iversen S, Vangen S, et al. (2017) Menopausal hormone therapy and risk of melanoma: Do estrogens and progestins have a different role? Int J Cancer 141(9): 1763-1770.

5. Rozenberg S, Fellemans C, Kroll M, Vandromme J (2000) The menopause in Europe. Int J Fertil Womens Med 45(2): 182-189.

6. Gold EB (2011) The timing of the age at which natural menopause occurs. Obstet Gynecol Clin North 38(3): 425-440.

7. Cobin RH, Goodman NF (2017) American association of clinical endocrinologists and american college of endocrinology position statement on menopause-2017 update. Endocr Pract 23(7): 869-880.

8. Anagnostis P, Galanis P, Chatzistergiou V, Stevenson JC, Godsland IF (2017) The effect of hormone replacement therapy and tibolone on lipoprotein (a) concentrations in postmenopausal women: A systematic review and meta-analysis. Maturitas 99: 27-36.

9. Parish SJ, Gillespie JA (2017) The evolving role of oral hormonal therapies and review of conjugated estrogens/bazedoxifene for the management of menopausal symptoms. Postgrad Med 129(3): 340-351.

10. Jyotsna VP (2013) Postmenopausal hormonal therapy: Current status. Indian J Endocrinol Metab 17(Suppl 1): 45-49.

11. Manson J, Branch H (2014) The women's health initiative: the latest findings from long-term follow-up. Womens Health (Lond) 10(2): 125128.

12. Reinhardt RA, Payne JB, Maze CA, Patil KD, Gallagher SJ, et al. (1999) Influence of estrogen and osteopenia/osteoporosis on clinical periodontitis in postmenopausal women. J Periodontol 70(8): 823-828.

13. Ronderos M, Jacobs DR, Himes JH, Pihlstrom BL (2000) Associations of periodontal disease with femoral bone mineral density and estrogen replace- ment therapy: cross-sectional evaluation of US adults from NHANES III. J Clin Periodontol 27(10): 778-786.

14. Civitelli R, Pilgram TK, Dotson M, Muckerman J, Lewandowski N, et al. (2002) Alveolar and postcranial bone density in postmenopausal women receiving hormone/estrogen replacement therapy. Arch Intern Med 162(12): 1409-1415.

15. Cekici A, Baser U, Isik G, Akhan SE, Issever H, et al. (2015) Periodontal treatment outcomes in post menopausal women receiving hormone replacement therapy. J Istanb Univ Fac Dent 49(3): 39-44.

16. Tarkkila L, Kari K, Furuholm J, Tiitinen A, Meurman JH (2010)
Periodontal disease-associated micro-organisms in peri-menopausal and post-menopausal women using or not using hormone replacement therapy. A two-year follow-up study. BMC Oral Health 10: 10.

17. Sultan N, Rao J (2011) Association between periodontal disease and bone mineral density in postmenopausal women: a cross sectional study. Med Oral Patol Oral Cir Bucal 16(3): 440-447.

18. Pepelassi E, Nicopoulou-Karayianni K, Archontopoulou AD, Mitsea A, Kavadella A (2012) The relationship between osteoporosis and periodontitis in women aged 45-70 years. Oral Dis 18(4): 353-359.

19. Bertulucci Lde A, Pereira FM, de Oliveira AE, Brito LM, Lopes FF (2012) Periodontal disease in women in post-menopause and its relationship with osteoporosis. Rev Bras Ginecol Obstet 34(12): 563-567.

20. Ignasiak Z, Radwan-Oczko M, Rozek-Piechura K, Cholewa M (2016) Analysis of the relationships between edentulism, periodontal health body composition, and bone mineral density in elderly women. Clin Interv Aging 11: 351-356.

21. Barreiro de LA A, Vázquez KF D, Méndez CJ, Mendoza DJ, Padrón LÁO, et al. (2014) The relationship of nutritional status, body and mandibular bone mineral density, tooth loss and fracture risk (FRAX) in pre-and postmenopausal women with periodontitis. Nutr Hosp 29(6): 14191426.

22. Singh A, Sharma RK, Siwach RC, Tewari S, Narula SC (2014) Association of bone mineral density with periodontal status in postmenopausal women. J Investig Clin Dent 5(4): 275-282.

23. Taguchi A, Sanada M, Suei Y, Ohtsuka M, Nakamoto T, et al. (2004) Effect of estrogen use on tooth retention, oral bone height, and oral bone porosity in Japanese postmenopausal women. Menopause 11(5): 556562.

24. Bollen AM, Taguchi A, Hujoel PP, Hollender LG (2004) Number of teeth and residual ridge height in subject with a history of self reported osteoporotic fractures. Osteoporos Int 15(12): 970-974.

25. Brasil SC, Santos RM, Fernandes A, Alves FR, Pires FR, et al. (2017) Influence of oestrogen deficiency on the development of apical periodontitis. Int Endod J 50(2): 161-166.

26. Krall EA, Hughes BD, Hannan MT, Wilson PW, Kiel DP, et al. (1997) Postmenopausal estrogen replacement and tooth retention. Am J Med 102(6): 536-542.

27. Meisel P, Reifenberger J, Haase R, Nauck M, Bandt C, et al. (2008) Women are periodontally healthier than men, but why don't they have more teeth than men? Menopause 15(2): 270-275.

28. Paganini-Hill A (1995) The benefits of estrogen replacement therapy on oral health. The Leisure World cohort. Arch Intern Med 155(21): 23252329.

29. Grodstein F, Colditz GA, Stampfer MJ (1996) Post-menopausal hormone use and tooth loss: a prospective study. J Am Dent Assoc 127(3): 370377. 